\title{
Action and coping plans related to the behavior of adherence to oral antidiabetic medication
}

\author{
Planos de ação e de enfrentamento de obstáculos relacionados ao \\ comportamento de adesão aos antidiabéticos orais \\ Danilo Donizetti Trevisan ${ }^{1}$ (D), Thaís Moreira São-João² (D), Marília Estevam Cornélio² (D), Maria Rui Miranda \\ Grilo Correia de Sousa ${ }^{3}$ (D), Roberta Cunha Matheus Rodrigues² (D), Maria Helena de Melo Lima² (D)
}

\begin{abstract}
Study Design: This mixed-methods study. Objective: To describe action plans related to the behavior of adherence to oral antidiabetic medications produced by people with type 2 diabetes mellitus and identify the challenges and coping strategies for the establishment of this behavior. Methods: The study followed-up 44 people with type 2 diabetes mellitus who used oral antidiabetic medications from southeast Brazil. Adults were invited to build action and coping plans based on the Implementation Intention Theory. The plans were quantitative and qualitatively analyzed. Results: Action plans included three major themes: (1) binding oral antidiabetic medication to time markers or the sleep/wake cycle; (2) in specific environments; (3) associated with daily life activities. The motivation for coping with the perceived barriers focused on placing the pills in visible places, asking for help from family members, establishing a routine and feeding properly. Conclusions: The most effective way to manage satisfactory oral antidiabetic medication adherence seems to be recognizing the perceived barriers by patients. The implementation of specific and individualized action and coping plans to overcome perceived barriers was the stark difference.
\end{abstract}

Keywords: Type 2 Diabetes Mellitus; Medication Adherence; Hypoglycemic Drugs; Planning Techniques; Nursing.

\section{RESUMO}

Desenho do estudo: Estudo de método misto. Objetivo: Descrever planos de ação relacionados ao comportamento de adesão aos antidiabéticos orais elaborados por pessoas com diabetes mellitus tipo 2 e identificar as barreiras percebidas e respectivas estratégias de enfrentamento para efetivação desse comportamento. Métodos: 0 estudo envolveu 44 pessoas com diabetes mellitus tipo 2 que utilizavam antidiabéticos orais na região sudeste do Brasil. Adultos foram convidados a construir os planos de ação e de enfrentamento de obstáculos baseados sobre a Teoria da Ativação da Intenção. Os planos foram analisados quantitativa e qualitativamente. Resultados: Os planos de ação incluíram três temas principais: (1) Associar a tomada dos antidiabéticos orais aos marcadores de tempo ou ao ciclo de sono / vigília; (2) em ambientes específicos; (3) associados às atividades de vida diária. Os planos de enfrentamento das barreiras percebidas centraram-se em colocar os comprimidos em locais visíveis, pedir ajuda aos familiares para evitar esquecimento, estabelecer rotina e alimentar-se adequadamente. Conclusões: A forma mais eficaz de manejar a tomada de antidiabéticos orais de modo satisfatório parece ser o reconhecimento das barreiras percebidas pela própria pessoa. A implementação de ações específicas e individualizadas bem como de planos de enfrentamento para superar as barreiras percebidas foi o diferencial neste estudo.

Palavras-chave: Diabetes Mellitus tipo 2; Adesão à Medicação; Hipoglicemiantes; Técnicas de Planejamento; Enfermagem.

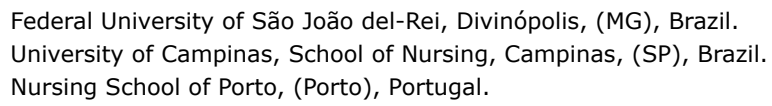




\section{INTRODUCTION}

Adherence to drug treatment is considered a determining factor for the successful treatment of non-communicable diseases (NCDs), although studies indicate that $17 \%$ up to $60 \%$ of patients - of all ages, sexes and ethnicities, and different health problems - do not adhere to their medications as prescribed ${ }^{1,2}$. Studies have presented great variation regarding oral antidiabetic medications (OADs), both in developed and developing countries (from $38.5 \%$ up to $89.7 \%$ ), about its adherence ${ }^{3-7}$. Discontinuance of medication treatment can be considered a frequent problem in Type 2 Diabetes Mellitus (T2DM) patients and, consequently, contribute to inadequate glycemic control and to higher chances of disease complications ${ }^{8}$.

Several studies have highlighted the need for identifying determinants and barriers related to $O A D$ adherence ${ }^{3,6,7}$. In this sense, the Theory of Planned Behavior (TPB $)^{9}$ is an extensively used theoretical reference in the study of health behaviors, including adherence to $\mathrm{OADs} 3,6,7,10$. This theory assumes that the intention (motivation) is the main determinant of behavior and that people with positive intention have higher chances of performing the desired behavior $^{9}$.

However, studies show that people, even with positive intention, often fail in accomplishing the desired behavior when difficult or complex barriers/ obstacles are found ${ }^{11-13}$ even in the adherence to $\mathrm{OADs}^{7}$. Therefore, interventions must be planned and implemented with aims to help motivated people performing the desired behavior ${ }^{14}$.

Considering this perspective, Gollwitzer ${ }^{15}$ proposed the "Implementation Intentions" as a theory to help people with positive intention to accomplish desired behaviors. This theory allows the individual to establish a relationship between specific situations that may prevent the behavior from being performed and the possible planned responses to these situations ${ }^{15}$. The Implementation Intentions can be performed through action planning, in which the person identifies where, how and when he/she will perform the behavior and through coping planning, focused on risk situations or barriers that may prevent, interfere or impede the accomplishment of the target behavior or the implementation of the planned actions. This strategy is an independent cognitive planning and comprises the mental connection between the anticipation of possible risk situations for the noncompletion of the planned behavior, as well as the possible coping responses to overcome these risk situations or barriers ${ }^{11,15}$.

A previous studies ${ }^{10,16}$ showed the effects of the Implementation Intentions theory in promoting adherence to OADs in people with T2DM under primary health care, evidencing an increase in adherence after the intervention. However, the action and coping plans that were raised were not described previously elsewhere. These plans can be considered guiding and introductory to encourage people with T2DM, alone or together with family or friends, to plan the taking of OADs in a way that is possible in their reality and to repeat this behavior in order to become a habit and, consequently, reduce glycemic levels. Knowing these plans by health professionals and managers, mainly nurses, doctors, and pharmacists, can enable these professionals to address these strategies in consultations with people with T2DM and promote adherence in practical scope.

Thus, this study aims to present the action plans related to the adherence behavior to oral antidiabetic medicines prepared by T2DM patients under follow-up in primary health care and to describe the perceived barriers and their coping strategies to accomplish this behavior. To the best of our knowledge, there are no studies that have presented action and coping plans to promote of adherence to OADs, especially in people with T2DM under primary health care.

\section{METHODS}

\section{Design, population and study location}

This mixed-methods study is derived from a previously single-blind randomized controlled study (RCT) with parallel groups (Trial registration REBEC - RBR-439f77), which assessed the effect of the Implementation Intentions Theory on the promotion of adherence to OADs among people 
with T2DM under follow-up in primary health care $^{16}$. Participants were recruited in two primary health care units in the southeastern region of Brazil, between February and December 2016. Inclusion criteria were: age $\geq 18$ years; to be under continuous OADs use for at least six months; positive score to adhere to T2DM treatment in the intention scale ( $\geq$ to 4 ) and have the ability to read and write in Brazilian Portuguese. Cognitive status was assessed through a 10-item questionnaire adapted from a previous study ${ }^{17}$. This study had two groups - intervention group (IG) and control group (CG) - throughout 15 weeks, with six data collection steps. The detailed methodology can be assessed elsewhere ${ }^{10,16}$. Only participants from the IG were included in the analysis of the present study, since the action and coping plans were filled only by this subsample.

\section{Action and coping planning}

The construction of plans was based on theoretical assumptions of Implementation Intentions ${ }^{15}$, through the elaboration of action planning and coping planning, considering their respective overcoming strategies. Participants were asked to fill out, with the help of the researcher, a form in which up to three action plans about when, where and how (action planning) it was intended to take the OADs for the next two months. Up to three possible obstacles for the accomplishment of the behavior and one to three coping strategies (coping planning) were also raised. Both the action and copping plans were manually recorded in a spreadsheet by the researcher and individually filed for further reference throughout the monitoring process.

\section{Variables and instruments}

1. Sociodemographic and clinical data: identification variables were collected, sociodemographic profile (sex, age, marital status, educational level, employment status, family arrangement, individual and family income) and clinical characterization (comorbidities, time of diagnosis of T2DM, prescribed treatment, measurement of glycated hemoglobin (A1C), current medical prescription, use of OADs and access to the medicines) were made through interviews in a restricted environment.

2. Behavior of adherence to OADs: was measured through an instrument created and used in a previous study ${ }^{7}$ based on the TPB $^{9}$. The instrument is composed of a single question and a four-point Likert-type scale and the answers vary from 1 (rarely or never) up to 4 (every day or almost every day of the week).

3. Measurement of adherence to OADs: was obtained through the Brazilian instrument Global Evaluation of Medication Adherence $(\text { GEMA })^{7}$, which classifies adherence proportions as appropriate dose ( $\geq 80 \%$ of the prescribed dosage) or insufficient dose ( $<80 \%$ of the prescribed dosage). The overall evaluation of adherence was made in four groups considering medical prescription: (Group I), adequate doses and care procedures; (Group II), adequate doses and inadequate care procedures; (Group III), inadequate doses and adequate care procedures; (Group IV), inadequate doses and care procedures.

4. Intention: measured through an instrument composed of six questions with a five-point Likert-type scale, which was previously created $^{7}$ and based on the TPB ${ }^{9}$. The arithmetic mean of the scores measured in six items was calculated to obtain the mean of intent. Participants with a mean score greater than or equal to 4 were considered as having a positive intention.

\section{Sample size}

Sample estimation was performed for the $\mathrm{RCT}^{16}$. The Chi-square test was used for such, adopting $80 \%$ power and $1.25 \%$ significance level. The significance level was determined after applying the Bonferroni criterion. The estimated sample was of 37 individuals for each group. Considering a $20 \%$ loss rate, the final sample size was at least 44 individuals for each group. 


\section{Data analysis}

The characterization data of the participants was submitted to descriptive statistical analyses. The developed plans were analyzed according to recommendations for content analysis in the context of theories on the study of behavior, being subjected to qualitative and quantitative analyses corresponding to the elaboration of one list for the action plans, one for the anticipated obstacles and one for coping plans ${ }^{18}$. Following, they were grouped by similarity of themes or ideas, enabling the frequency with which they were reported.

\section{Ethical aspects}

The study was approved by the local Research Ethics Committee (Document $n$. 47962915.4.0000.5404). The main study that originated this one followed the recommendations of the Consolidated Standards of Reporting Trials (CONSORT) ${ }^{19}$ and was registered in the International Clinical Trials Registration Platform (ICTPR) via the Brazilian Clinical Trials Registry (ReBec), under the record RBR-439f77.

\section{RESULTS}

\section{Sample characterization and characterization of adherence to oral antidiabetic medicines}

Study participants were 44 people with T2DM under primary health care. The sample was composed mainly of women, with low education and in the use of polypharmacy. At baseline, only $27.3 \%$ of participants were considered as adherents from the overall adherence assessment (Table 1).

Table 1

Sociodemographic and clinical characteristics.

\begin{tabular}{|c|c|}
\hline Patients' characteristics & Baseline $(n=44)$ \\
\hline Age (years), Mean (SD*) & $61.1(8.9)$ \\
\hline \multicolumn{2}{|l|}{ Gender } \\
\hline Female $(n),(\%)$ & $30(68.2)$ \\
\hline \multicolumn{2}{|l|}{ Race } \\
\hline White (n), (\%) & $33(75.0)$ \\
\hline \multicolumn{2}{|l|}{ Marital status $(n),(\%)$} \\
\hline Living with a partner & $29(65.9)$ \\
\hline Living without a partner & $15(34.1)$ \\
\hline Education level (years), mean (SD) & $6.4(4.9)$ \\
\hline \multicolumn{2}{|l|}{ Occupation $(n),(\%)$} \\
\hline Works & $17(38.6)$ \\
\hline Does not work & $27(61.4)$ \\
\hline Monthly household income, mean (SD) & $3.0(1.7)$ \\
\hline $\mathrm{BMI}{ }^{\neq} \mathrm{kg} / \mathrm{m}^{2}$, mean $(\mathrm{SD})$ & $29.8(5.7)$ \\
\hline Associated clinical conditions, mean (SD) & $2.2(0.9)$ \\
\hline Hypertension (n), (\%) & $34(77.2)$ \\
\hline Dyslipidemia (n), (\%) & $32(72.7)$ \\
\hline Cardiovascular problems $(n),(\%)$ & $11(25.0)$ \\
\hline Time of diagnosis of T2DM (years), mean (SD) & $6.8(6.7)$ \\
\hline A1c, mean (SD) & $7.3(0.8)$ \\
\hline Number of medications used, mean (SD) & $5.2(1.8)$ \\
\hline Number of oral antidiabetic medicines, mean (SD) & $1.5(0.6)$ \\
\hline Measurement of intention $(\geq 4)$, mean (SD) & $4.3(0.4)$ \\
\hline \multicolumn{2}{|l|}{ Measurement of behavior } \\
\hline Every day or almost every day $(n),(\%)$ & $30(68.2)$ \\
\hline \multicolumn{2}{|l|}{ Adherence proportion $(n),(\%)$} \\
\hline$\geq 80 \%$ dose & $23(52.3)$ \\
\hline \multicolumn{2}{|l|}{ Overall evaluation of the adherence $(n),(\%)$} \\
\hline Adherents & $12(27.3)$ \\
\hline
\end{tabular}




\section{Description of action and coping planning}

Considering the plans related to taking the medicine, these were associated with taking the medicines at certain time counters, such as before or after meals (breakfast, lunch and dinner) or associating them to the sleep/wake cycle (waking up and before going to sleep). Regarding where to take the OADs, most plans were built by referencing specific home location (bedroom or kitchen). Regarding how to take the medicines, plans associated with activities of daily living ( $A D L$ ) were the most common, such as during toothbrushing or bathing, and taking the medicines with a glass of water, juice or tea (Table 2).

Different situations that may occur in everyday life, during work or leisure, were related to the obstacles of accomplishing the behavior. In daily life, the most frequently reported barriers were forgetfulness and the presence of adverse events (AEs). Coping plans designed to overcome obstacles in daily life were: placing pills in strategic locations, feeding every three hours in small portions, establishing a routine for meals and associating it to taking the OADs (Table 3).

\section{Table 2}

Presentation of action plans elaborated by people with type 2 diabetes mellitus.

\begin{tabular}{|c|c|c|}
\hline Action plans & $\mathbf{n}$ & $\%$ \\
\hline \multicolumn{3}{|l|}{ When (time markers) } \\
\hline Associate the taking of medicines after meals (breakfast, lunch and dinner) & 43 & 97.7 \\
\hline Associate the taking of medicines before meals (breakfast, lunch and dinner) & 25 & 56.8 \\
\hline Associate the taking of medicines to the sleep/wake cycle (e.g., fasting or before going to sleep) & 24 & 54.5 \\
\hline \multicolumn{3}{|l|}{ Where (in which place) } \\
\hline Bedroom (e.g., next to the nightstand) & 16 & 36.4 \\
\hline Home kitchen (e.g., next to the fridge or cupboard or water fountain) & 10 & 22.8 \\
\hline Anywhere & 9 & 20.4 \\
\hline Work kitchen & 8 & 18.2 \\
\hline Work (e.g., office desk, locker room) & 4 & 9.1 \\
\hline Living room & 4 & 9.1 \\
\hline Restaurant & 3 & 6.8 \\
\hline \multicolumn{3}{|l|}{ How } \\
\hline $\begin{array}{l}\text { Associate the taking of medicines to activities of daily living (e.g., when preparing breakfast, } \\
\text { toothbrushing) }\end{array}$ & 20 & 45.4 \\
\hline Associate the taking of medicines to a glass of water/juice or sugarless tea & 20 & 45.4 \\
\hline After performing household chores (e.g., when doing the dishes) & 5 & 11.4 \\
\hline Associate the taking of medicines to the schedules of television programs & 4 & 9.1 \\
\hline Before walking the pets & 4 & 9.1 \\
\hline
\end{tabular}


Table 3

Perceived barriers and coping plans elaborated by patients regarding daily life, work and leisure activities.

\begin{tabular}{|c|c|c|c|c|c|}
\hline Perceived obstacles/barriers & $\mathbf{n}$ & $\%$ & Coping plans & $\mathbf{n}$ & $\%$ \\
\hline \multicolumn{6}{|l|}{ Forgetfulness } \\
\hline \multirow[t]{2}{*}{$\begin{array}{l}\text { Forgetting to take the medicines at the } \\
\text { prescribed times }\end{array}$} & 21 & 47.7 & $\begin{array}{l}\text { Placing the pills in strategic locations (on } \\
\text { top of the nightstand, refrigerator or kitchen } \\
\text { cupboard) }\end{array}$ & 17 & 38.6 \\
\hline & & & $\begin{array}{l}\text { Asking for a family member to help in } \\
\text { remembering to take the medicines }\end{array}$ & 4 & 9.1 \\
\hline \multirow[t]{2}{*}{$\begin{array}{l}\text { Absence of a family member to help } \\
\text { the patient remember to take his/her } \\
\text { medicines }\end{array}$} & 14 & 31.8 & $\begin{array}{l}\text { Register the drug name and its respective } \\
\text { time on a piece of paper and place it as a } \\
\text { note on the fridge }\end{array}$ & 9 & 20.4 \\
\hline & & & $\begin{array}{l}\text { Prepare the medicines in pill organizers } \\
\text { during the morning for the whole day }\end{array}$ & 5 & 11.4 \\
\hline $\begin{array}{l}\text { Not collecting the medicines at the health } \\
\text { service or popular pharmacies }\end{array}$ & 7 & 15.9 & $\begin{array}{l}\text { Asking for a family member to collect the } \\
\text { medicines }\end{array}$ & 7 & 15.9 \\
\hline
\end{tabular}
service or popular pharmacies

\section{Presence of Adverse Events}

Hypoglycemia

Dry mouth and thirst

Diarrhea or occasional indigestion

$\begin{array}{lllll}14 & 31.8 & \text { Feeding every three hours in small portions. } & 14 & 31.8\end{array}$ Eating a small snack between the large meals

$\begin{array}{lllll}7 & 15.9 & \text { Drinking at least two liters of water a day } & 7 & 15.9\end{array}$

$\begin{array}{lllll}5 & 11.4 & \text { Understanding that AEs can occur; search for } & 5 & 11.4\end{array}$ referral a doctor and nurse to describe the problem and, if possible, replace the drug

Absence of routine

$\begin{array}{lllll}6 & 13.7 & \text { Standardizing meal times and associating } & 6 & 13.7\end{array}$ them to the taking of medicines

Problems related to medical prescription

Lack of understanding of the medical prescription

11.4 Searching for a nurse or doctor of the health service and asking any questions about the medicines

Only being able to read block letters

6.8 Asking the doctor or nurse to rewrite the prescription in a clearer manner and using block letters

Use of polypharmacy and change of medicines

3

6.8 Asking for help from a family member to organize the medicines Organizing each of the doses in pill organizers everyday

Unawareness of the treatment

Difficulty to understand the reason/ purpose of the prescribed drug

$\begin{array}{lllll}5 & 11.4 & \text { Searching for a health care professional from } & 4 & 9.1\end{array}$ the unit or participating in diabetes groups and understanding the reason for taking each drug and how they act on the body Self-stimulating to control diabetes

Believing that diabetes will be cured without any intervention

$\begin{array}{lllll}1 & 2.3 & \text { Understanding that diabetes has no cure and } & 1 & 2.3\end{array}$ needs treatment to avoid complications

\section{Emotional aspects}

Sadness caused by the death of spouse or family issues

Other barriers

Unavailability of the drug in the health unit

4

Difficulty to swallow the pill due to its large aspect (metformin)

2
4.5 Increasing the bond with friends and family

24.5

9.1 Searching in another close health unit or going to a popular pharmacy with the prescription and personal documents

4.5 Understanding that the metformin pill cannot be crushed or chewed due to pharmacokinetic characteristics. Searching for the medical staff to change the drug or dosage if necessary 


\section{DISCUSSION}

This study aimed to describe the action plans related to the behavior of adherence to OADs produced by T2DM patients under follow-up in primary health care, as well as to identify perceived barriers and their coping strategies to accomplish this behavior. Our results suggest that the most effective way to manage OADs adherence is recognizing the barriers perceived by patients and the development of strategies to improve the management of drug-taking, focusing on the patients' routine, activities of daily living, work and leisure was fundamental to improve their adherence.

The implementation of specific strategies to overcome these barriers, instead of the classic approach of simplifying a complex medication regimen, was the difference in our study, corroborating with the recommendations of the latest diabetes care guidelines ${ }^{20}$.

Previous TPB-based studies ${ }^{3,6,7}$ showed that the low adherence to OADs by people with T2DM may be related to behavioral, normative and control beliefs. Thus, the preparation of action plans and planning based on the Implementation Intention strategy was crucial to assist participants and enable a positive intention on effective behavior and promotion of OADs adherence.

Despite the low level of education found in this study, both action and coping plans and the identification of barriers were designed by participants in conjunction with the researcher in a non-directive manner, following previous recommendations ${ }^{14}$. Evidence points that involving and valuing the patient's preferences for optimizing strategies in drug therapy management may increase engagement and motivation and, consequently, may increase the adherence to drug therapy ${ }^{21,22}$.

In several studies ${ }^{23-25}$, barriers such as forgetfulness, the presence of adverse events and difficulty establishing routines were some of the main reasons for non-adherence to medication in different scenarios, populations and health conditions. A previous study ${ }^{23}$ showed that people with T2DM do not take their medications when they feel ill, are too busy, and cannot follow a previous routine, especially when they have meals in appropriate times.
Barriers such as forgetfulness, lack of routine to have meals and coping with emotional situations were also present in our study in daily living situations, at work and during leisure. For such, the coping strategies proposed by the patients themselves focused on placing the pills in strategic places, asking for help from family members to remind them, eating every three hours, drinking at least two liters of water a day, standardizing meal times, increasing the bond with friends and relatives and keeping the medicines in the purse or wallet when running errands or performing leisure activities. In this sense, nurses must be mediators and facilitators for constructing these plans, significantly contributing to the management of T2DM and continuity of care for the disease.

Another relevant barrier found in this study was adverse events, such as hypoglycemia, dry mouth, thirst or diarrhea. This barrier seems to be very specific to the use of AODs and T2DM patients, and points to the need for health professionals to build a stronger relationship with patients and working closely in the monitoring of therapeutic plans to improve adherence rates, especially in people with comorbidities and in use of polypharmacy.

The findings showed that most action plans were associated with binding the taking of AODs to time markers or the sleep/wake cycle. Forgetfulness, the establishment of a routine and the presence of adverse events were the most prevalent barriers raised by patients. Coping plans were designed to consider daily activities, such as placing the pills in easy to spot places, establishing a routine and feeding properly. These were the most reported strategies to overcome the existing gap to accomplish the behavior. Targeted interventions that encourage reflection about changing behaviors are beneficial and meaningful to promoting adherence to OADs and as strategies to be used in clinical practice.

Although this study provides new evidence about the importance of strategies to promote adherence to OADs, there are some limitations. Our findings are not generalizable to other scenarios, such as tertiary services that care for more complex patients; a subjective measure was used, i.e., selfreport to evaluate adherence to OADs, despite using a validated instrument (GEMA) that, in addition to 
measuring the adherence proportion, also considers the overall evaluation of adherence. Future studies could incorporate objective adherence measures, such as monitoring serum levels of medicines, evaluating biochemical laboratory tests and directly quantifying the therapeutic plan.

Thus, efforts to understand the adherence to drug treatment can be considered daily challenges to be achieved, since the mechanisms involved in this behavior are still complex ${ }^{25}$. Future studies on the effectiveness of these behavioral strategies should be conducted with T2DM patients to refine these interventions, seeking their replication in clinical practice.

\section{CONCLUSION}

The most effective way to manage satisfactory OADs adherence seems to be recognizing the perceived barriers by patients, and the development of strategies to improve drug-taking management; with focus on people's routine, daily living activities, work and leisure. The implementation of specific and individualized action and coping plans to overcome perceived barriers, instead of the classic approach of simplifying a complex medication regimen, was the stark difference in this study, corroborating with worldwide recommendations for managing T2DM.

In conclusion, involving and valuing people with T2DM when managing strategies for adhering drug to therapy may increase engagement and motivation and, consequently, may increase the adherence to drug therapy; which leads to a better quality of life and more prolonged survival.

\section{REFERENCES}

1. Fernandez-Lazaro CI, García-González JM, Adams DP, Fernandez-Lazaro D, Mielgo-Ayuso J, Caballero-Garcia A, et al. Adherence to treatment and related factors among patients with chronic conditions in primary care: A crosssectional study. BMC Family Practice. 2019;20:132.

2. Sabaté E. Adherence to long-term therapies. World Health Organization. 2003.

3. Zomahoun HTV, Moisan J, Lauzier S, Guillaumie L, Grégoire J-P, Guénette L. Predicting Noninsulin Antidiabetic Drug Adherence Using a Theoretical Framework Based on the Theory of Planned Behavior in Adults With Type 2 Diabetes: A Prospective Study. Medicine. 2016;95(15):e2954.
4. Bruce SP, Acheampong F, Kretchy I. Adherence to oral anti-diabetic drugs among patients attending a Ghanaian teaching hospital. Pharmacy Practice. 2015;13(1):533.

5. Chew B-H, Hassan N-H, Sherina M-S. Determinants of medication adherence among adults with type 2 diabetes mellitus in three Malaysian public health clinics: a crosssectional study. Patient preference and adherence. 2015;9:639-48.

6. Guénette L, Breton MC, Guillaumie L, Lauzier S, Grégoire JP, Moisan J. Psychosocial factors associated with adherence to non-insulin antidiabetes treatments. Journal of Diabetes and its Complications. $2016 ; 30(2): 335-42$.

7. Jannuzzi FF, Cornélio ME, São-João TM, Gallani MC, Godin G, Rodrigues RCM. Psychosocial determinants of adherence to oral antidiabetic medication among people with type 2 diabetes. Journal of Clinical Nursing. 2020;29(5-6):909-21.

8. Jaam M, Ibrahim MIM, Kheir N, Awaisu A. Factors associated with medication adherence among patients with diabetes in the Middle East and North Africa region: A systematic mixed studies review. Diabetes Research and Clinical Practice. 2017;129:1-15.

9. Ajzen I. The theory of planned behavior. Organizational Behavior and Human Decision Processes. 1991;50(2):179-211.

10. Trevisan DD, São-João TM, Cornélio ME, Jannuzzi FF, Rodrigues RCM, Lima MHM. A randomized controlled trial on the effect of behavioral strategies for adherence to oral antidiabetic drugs: study protocol. Contemporary Nurse. 2017;53(6):658-68.

11. Wieber F, Thürmer JL, Gollwitzer PM. Promoting the translation of intentions into action by implementation intentions: behavioral effects and physiological correlates. Frontiers in Human Neuroscience. 2015;9:395.

12. Hagger MS, Luszczynska A, de Wit J, Benyamini $Y$, Burkert $S$, Chamberland $P E$, et al. Implementation intention and planning interventions in Health Psychology: Recommendations from the Synergy Expert Group for research and practice. Psychology and Health. 2016;31(7):814-39.

13. Marquardt $M K$, Oettingen G, Gollwitzer PM, Sheeran $P$, Liepert J. Mental contrasting with implementation intentions (MCII) improves physical activity and weight loss among stroke survivors over one year. Rehabilitation Psychology. 2017;62(4):580-90.

14. Sniehotta FF, Scholz U, Schwarzer R. Action plans and coping plans for physical exercise: a longitudinal intervention study in cardiac rehabilitation. British Journal of Health Psychology. 2006;11:23-37.

15. Gollwitzer PM. Implementation intentions: Strong effects of simple plans. American Psychologist. 1999;54(7):493-503.

16. Trevisan DD, São-João $T$, Cornélio $M$, Jannuzzi $F$, de Sousa $M R$, Rodrigues $R$, et al. Effect of an 'implementation intention' intervention on adherence to oral anti-diabetic medication in Brazilians with type 2 diabetes. Patient Education and Counseling. 2020;103(3):582-8.

17. Pfeiffer E. A short portable mental status questionnaire for the assessment of organic brain deficit in elderly patients. Journal of the American Geriatrics Society. $1975 ; 23(10): 433-41$. 
18. Godin G, Kok G. The theory of planned behavior: a review of its applications to health-related behaviors. American Journal of Health Promotion. 1996;11(2):87-98.

19. Schulz KF, Altman DG, Moher D. CONSORT 2010 statement: Updated guidelines for reporting parallel group randomized trials. Annals of Internal Medicine. 2010;152(11):726-32.

20. American Diabetes Association. 1. Improving care and promoting health in populations: Standards of medical care in diabetes-2019. Diabetes Care. 2019;42(Suppl 1):S7-12.

21. McSharry J, McGowan L, Farmer AJ, French DP. Perceptions and experiences of taking oral medications for the treatment of Type 2 diabetes mellitus: a systematic review and meta-synthesis of qualitative studies. Diabetic Medicine. 2016;33(10):1330-8.

22. Inzucchi SE, Bergenstal RM, Buse JB, Diamant $M$, Ferrannini $E$, Nauck $M$, et al. Management of hyperglycemia in type 2 diabetes, 2015: a patientcentered approach: update to a position statement of the American Diabetes Association and the European Association for the Study of Diabetes. Diabetes Care. 2015;38(1):140-9.

23. Islam SMS, Biswas T, Bhuiyan FA, Mustafa $K$, Islam A. Patients' perspective of disease and medication adherence for type 2 diabetes in an urban area in Bangladesh: a qualitative study. BMC Research Notes. 2017;10(1):131.

24. Al-Ramahi R. Adherence to medications and associated factors: A cross-sectional study among Palestinian hypertensive patients. Journal of Epidemiology and Global Health. 2015;5(2):125-32.

25. Martin LR, Feig C, Maksoudian CR, Wysong $K$, Faasse $\mathrm{K}$. A perspective on nonadherence to drug therapy: Psychological barriers and strategies to overcome nonadherence. Patient Preference and Adherence. 2018;12:1527-35.

\section{Acknowledgements}

We would like to acknowledge all patients who agreed to participate in the study.

\section{Conflict of interests}

The author(s) declared no potential conflicts of interest concerning the research, authorship, and/or publication of this article.

\section{Authors' contributions}

DDT, TMSJ and MEC: led the initial conceptual development of the study. Subsequent study conception and design. DDT data collection; DDT, TMSJ and MEC: contributed to discussion, wrote the manuscript, reviewed/edited the manuscript; MRMGCS, RCMR, MHML: contributed to discussion, wrote the manuscript, reviewed/edited the manuscript. All authors were involved in drafting the article and revising it critically for important intellectual content, and all authors approved the final version to be published.

\section{Funding}

No funding

Corresponding Author

Danilo Donizetti Trevisan

ddtrevisan@ufsj.edu.br

+5519988761906

Editor:

Prof. Dr Felipe Villela Gomes

Received in: July 18,2020

Approved in: Sept 2, 2020 